\section{Ultrasound in the screening of patients with cirrhosis with large varices}

The presence of varices reduces the survival of patients with cirrhosis, and the risk of bleeding is higher when large varices are present. ${ }^{12}$ Ultrasonography has been advocated as a screening test for portal hypertension. ${ }^{3}$ We have evaluated whether this non-invasive technique might be useful in predicting large varices.

\section{Patients, methods, and results}

Ultrasonography was performed in 164 consecutive patients with histologically proved non-ascitic cirrhosis. The diameters of the portal, splenic, and mesenteric veins were measured and endoscopy performed in all patients to detect varices. Varices were defined as large when they occupied more than one third of the oesophageal lumen. ${ }^{4}$ Commercially available real time equipment was used. The diameter of the portal vein was measured at the widest point directly in front of the vena cava on a scan in the sagittal plane. The diameters of the splenic and superior mesenteric veins were measured on scans in the transverse and sagittal planes respectively. Two independent observers performed the ultrasonography and the degree of agreement was evaluated.

The portal vein was visualised in all 164 patients, the splenic vein in 131 $(80 \%)$, and the mesenteric vein in $116(71 \%)$. In 148 patients $(90 \%)$ there was agreement between the two observers. In the remaining 16 patients there was disagreement within $1 \mathrm{~mm}$ : in this case the lower value was taken. The figure shows the diameters of the three veins and their relation to the presence of varices; there was a large overlap between patients with and
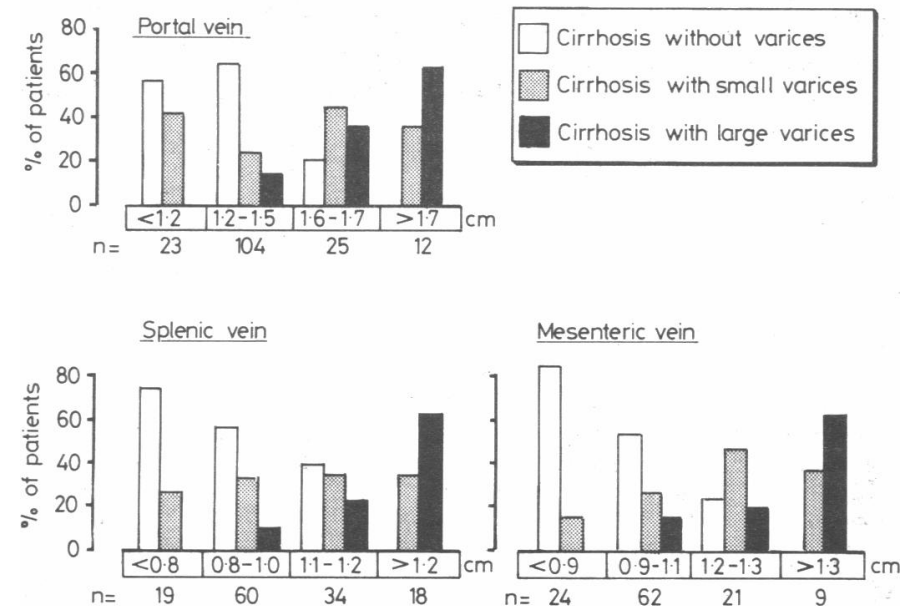

Relation between diameters of portal, splenic, and mesenteric veins and presence of varices.

without varices. No patient with large varices, however, had a portal vein $<1.2 \mathrm{~cm}$, a splenic vein diameter $<0.8 \mathrm{~cm}$, or a mesenteric vein diameter $<0.9 \mathrm{~cm}$. Thus we identified 32 patients without large varices. All patients had varices when the portal vein diameter was $>1.7 \mathrm{~cm}$, the splenic vein diameter $>1.2 \mathrm{~cm}$, or mesenteric vein diameter $>1.3 \mathrm{~cm}$; in each case two thirds of these patients had large varices.

\section{Comment}

Endoscopy is the preferred technique for diagnosing oesophageal varices and is frequently used to identify large varices to make a prognostic evaluation in patients with cirrhosis. Ultrasound has recently been shown to be useful for screening for portal hypertension. ${ }^{3}$

We evaluated the relation between the diameters of the portal, splenic, and mesenteric veins (echographic evaluation) and the presence of large varices (endoscopic evaluation). We could find no diameter above which the presence of large varices could be predicted with certainty; however, a portal vein diameter $>1.7 \mathrm{~cm}$, a splenic vein diameter $>1.2 \mathrm{~cm}$, or a mesenteric vein diameter $>1.2 \mathrm{~cm}$ indicated the presence of varices in every case; in most cases these varices were large. Similarly, we established a lower limit of the diameter of each vein below which the presence of large varices can be ruled out.

The mesenteric vein seems more useful than the others because it eliminated the possibility of large varices in $21 \%$ of the patients. The portal and splenic veins were less sensitive in excluding the presence of large varices. When the three veins were used together the possibility of large varices was eliminated in $20 \%$ of patients.

In conclusion we think that it is useful to screen all patients with cirrhosis with ultrasound in order to save some useless endoscopies.

${ }^{1}$ Pagliaro L, D'Amico G, Maringhini A, et al. Natural history of nonalcoholic cirrhosis. In: Orloff MJ, Stipa S, Ziparo V, eds. Medical and surgical problems of portal hypertension. London: Academic Press, 1980 : 109-17.

${ }^{2}$ Lebrec D, De Fleury P, Rueff B, Nahum H, Benhamou J. Portal hypertension, size of esophageal varices, and risk of gastrointestinal bleeding in alcoholic cirrhosis. Gastroenterology 1980;79:1139-44.

${ }^{3}$ Bolondi L, Gandolfi L, Arieti V, et al. Ultrasonography in the diagnosis of portal hypertension: diminished response of portal vessels to respiration. Radiology 1982;142:167-72.

${ }^{4}$ Beppu K, Inokvechi K, Koyanagy N, et al. Prediction of variceal hemorrage by esophageal endoscopy. Gastrointest Endosc 1981;27:213-8.

(Accepted 15 April 1983)

Istituto di Medicina Generale e Pneumologia, Cattedra di Patologia Speciale Medica dell'Università, Divisione di Medicina Interna dell'Ospedale V Cervello, Palermo, Italy

MARIO COTTONE, MD, research fellow

ELIO SCIARRINO, MD, medical registrar

MARIA PIA MARCENÒ, MD, research fellow

ALBERTO MARINGHINI, MD, medical registrar

GENNARO D'AMICO, MD, medical registrar

MARIO TRAINA, MD, research fellow

MARIANO AMUSO, MD, senior registrar

LUIGI PAGLIARO, MD, professor of medicine

Correspondence to: Dr Elio Sciarrino, Ospedale "V Cervello" Divisione di Medicina, Via Trabucco No 180, Palermo, Italy.

\section{Maternal smoking and anencephaly}

In 1979 Evans, Newcombe, and Campbell published a valuable analysis $^{1}$ of the Cardiff Birth Survey, showing little association between maternal smoking in pregnancy and most types of those congenital defects which are recognised neonatally. They did, however, find a weak association with anencephaly (132 cases) and spina bifida (178 cases), even after controlling for social class. We present an analysis of 491 pregnancies resulting in the birth of a singleton anencephalic.

\section{Methods and results}

The data were collected as part of the 1958 British Perinatal Mortality Survey and are described fully elsewhere. ${ }^{2}$ In brief, factors relating to all 7117 stillbirths and neonatal deaths occurring in Britain during March, April, and May 1958 were compared with all 16944 singleton deliveries in Britain during one week of March 1958. This second group served as the control population. Data collected included detailed information on the mother's smoking history. Social class codes were derived from the husband's occupation.

From the information collected we calculated the anencephalic incidence per 1000 births if the mother smoked at the start of pregnancy as 2.89 (SE $0 \cdot 19$ ), which was significantly greater than that found if the mother did not smoke $(2 \cdot 18(\mathrm{SE} 0.13) ; \mathrm{p}<0.05)$. The table shows that there was some evidence for a trend with dose.

As in other studies, however, the incidence of anencephaly in this survey rose sharply as social class fell, ${ }^{3}$ being 1.42 in classes I and II, 2.39 in social class III, and 3.16 in classes IV and V. The proportion of the control population of mothers smoking in early pregnancy also exhibited a trend with social class (32\% in I and II, $41 \%$ in III, and $47 \%$ in IV and V). Indirect standardisation for each of the five social classes (table) resulted in no significant differences between the observed and expected numbers in each smoking group. 


\section{Comment}

Available evidence suggests that although maternal smoking is demonstrably associated with reduced birth weight and perinatal loss, ${ }^{4}$ there is little to suggest that major malformations of the central nervous system are associated with the habit. This is relevant in the current debate on the efficacy of multivitamin supplements given

Estimated percentage incidence of anencephaly by maternal smoking habit at start of pregnancy

\begin{tabular}{cccc}
\hline \multirow{2}{*}{$\begin{array}{c}\text { Maternal } \\
\text { smoking } \\
\text { (cigarettes/day) }\end{array}$} & $\begin{array}{c}\text { Estimated } \\
\text { incidence } \\
(\text { SE) }\end{array}$ & \multicolumn{2}{c}{ No of cases of anencephaly } \\
\cline { 3 - 5 } & & Observed & Expected* \\
\hline None & $2 \cdot 18(0 \cdot 13)$ & 261 & $282 \cdot 8$ \\
$1-9$ & $2 \cdot 77(0 \cdot 25)$ & 122 & 106.3 \\
$\geqslant 10$ & $3 \cdot 05(0.30)$ & 100 & 97.8 \\
\hline Total, including not known & $2 \cdot 41(0 \cdot 11)$ & 491 & 491.0 \\
\hline
\end{tabular}

*After indirect standardisation for social class.

before conception to women who have had an infant affected with anencephaly or spina bifida, since smokers are known to have low serum vitamin C concentrations. ${ }^{5}$ Evidence from our study therefore suggests that lack of this particular vitamin was not of importance in the aetiology of anencephaly.

We are extremely grateful to the National Birthday Trust Fund for permission to use data from the First Perinatal Mortality Survey, and to Yasmin Iles for typing the manuscript.

${ }^{1}$ Evans DR, Newcombe RG, Campbell H. Maternal smoking habits and congenital malformations: a population study. $B r \operatorname{Med} \mathcal{f} 1979$;iv : $171-3$.

${ }^{2}$ Butler NR, Bonham DG. Perinatal mortality: first report of the 1958 British Perinatal Mortality Survey. Edinburgh: E \& S Livingstone, 1963.

${ }^{3}$ Fedrick J. Anencephalus: variation with maternal age, parity, social class and region in England, Scotland and Wales. Ann Hum Genet $1970 ; 34: 31-8$

+ Butler NR, Alberman ED. Perinatal problems. Edinburgh: E \& S Livingstone, 1969

${ }^{5}$ Hoefel OS. Plasma vitamin $\mathrm{C}$ levels in smokers. Int $\mathcal{f}$ Vitam Nutr Res $1977 ; 16: 127-37$.

(Accepted 11 May 1983)

University Department of Child Health, Royal Hospital for Sick Children, Bristol BS2 8BJ

JEAN GOLDING, MD, Wellcome Trust senior lecturer

N R BUTLER, DCH, FRCOG, professor of child health

Correspondence to: Dr Jean Golding.

\section{Serum IgA concentration and hepatotoxicity in rheumatoid arthritis treated with azathioprine}

A selective IgA deficiency in rheumatoid arthritis may be associated with striking improvement of disease activity. ${ }^{1}$ A selective IgA deficiency occurring with second line treatment is also associated with both improvement in disease and the development of drug toxicity. ${ }^{2}$ We therefore measured baseline IgA concentrations in patients with rheumatoid arthritis severe enough to require a variety of second line agents to determine whether a low IgA concentration before treatment predisposed to drug toxicity.

\section{Patients, methods, and results}

Six groups of 15 patients with classic or definite rheumatoid arthritis (American Rheumatism Association criteria) were treated with penicillamine $(125 \mathrm{mg} /$ day increasing to $500 \mathrm{mg} /$ day by the eighth week of treatment), sodium aurothiomalate $(50 \mathrm{mg} /$ week intramuscularly and $50 \mathrm{mg} / \mathrm{month}$ maintenance dose after a total of $1 \mathrm{~g})$, azathioprine $(1.5 \mathrm{mg} / \mathrm{kg} / \mathrm{day})$, sul-
Mean baseline data (SEM) in patients with low $(-150 \mathrm{IU} / \mathrm{ml})$ and high $(>400 \mathrm{IU} / \mathrm{ml})$ initial $\mathrm{Ig} A$ concentrations

\begin{tabular}{|c|c|c|c|}
\hline & \multirow[b]{2}{*}{$\begin{array}{l}\text { High } \\
\text { baseline } \\
\text { IgA } \\
(\mathrm{n}=12)\end{array}$} & \multicolumn{2}{|c|}{ Low baseline IgA } \\
\hline & & Total $(\mathrm{n}=11)$ & $\begin{array}{l}\text { With subsequent } \\
\text { hepatotoxicity } \\
(\mathrm{n}=4)\end{array}$ \\
\hline $\begin{array}{l}\mathrm{IgA}(\mathrm{IU} / \mathrm{ml}) \\
\mathrm{C} \text { reactive protein }(\mathrm{mg} / 100 \mathrm{ml})\end{array}$ & $\begin{array}{l}530(30) \\
4.76(0.93)\end{array}$ & $\begin{array}{l}109(9) \\
5.27(1.81)\end{array}$ & $\begin{aligned} & 127(11) \\
& 4.84(0.62)\end{aligned}$ \\
\hline $\begin{array}{l}\text { Erythrocyte sedimentation rate } \\
\quad \text { (mm in first hour) } \\
\text { Y-glutamyltransferase (U/1) } \\
\text { Alkaline phosphatase (U/I) } \\
\text { Aspartate transaminase (U/1) } \\
\text { Age (years) }\end{array}$ & $\begin{array}{l}69(8) \\
31(6) \\
77 \cdot 4(8 \cdot 5) \\
22(6) \\
54(2)\end{array}$ & $\begin{array}{l}58(9) \\
35(9) \\
69 \cdot 6(14 \cdot 2) \\
18(1) \\
57(7)\end{array}$ & $\begin{array}{l}62(9) \\
45(14) \\
63 \cdot 2(17 \cdot 0) \\
18(4) \\
61(3)\end{array}$ \\
\hline
\end{tabular}

phasalazine $(1.5-3.0 \mathrm{~g} /$ day), clozic $(300 \mathrm{mg} /$ day), and hydroxychloroquine sulphate $(200 \mathrm{mg}$ twice daily) for 24 weeks. The only other drugs allowed were non-steroidal anti-inflammatory agents (usually enteric coated aspirin). Before treatment the mean $\mathrm{C}$ reactive protein concentration and erythrocyte sedimentation rate (both useful indicators of disease activity) and IgA concentration were comparable for all six treatment groups. The mean ages and the sex ratios of patients were also comparable. Patients with a low serum IgA concentration ( $\leqslant 150 \mathrm{IU} / \mathrm{ml}$ ) (10 women, one man) and those with a high serum IgA concentration $(400 \mathrm{IU} / \mathrm{ml}$ ) (six women, six men) were then compared (table). Hepatotoxicity was detected by significant increases in serum aspartate transaminase, $\gamma$-glutamyltransferase, and alkaline phosphatase activities (though the latter two may also reflect disease activity, being slightly raised in $20-25 \%$ of patients ${ }^{3}$ ); nephrotoxicity was detected by increases in plasma urea and creatinine concentrations.

There was no significant difference in the incidence of toxic side effects between patients with low and high IgA concentrations except in patients taking azathioprine. The four patients withdrawn from azathioprine treatment because of liver toxicity, however, had initial IgA concentrations ranging from 98 to $150 \mathrm{IU} / \mathrm{ml}$, while the remaining 11 patients had initial IgA concentrations ranging from 210 to $600 \mathrm{IU} / \mathrm{ml}$. The low baseline IgA concentrations varied little up to the onset of hepatotoxicity. In all four patients hepatotoxicity was detected by an approximately fourfold increase in $\gamma$-glutamyltransferase activity, a threefold increase in serum aspartate transaminase activity, and a doubling of the alkaline phosphatase activity in the absence of a fall in the erythrocyte sedimentation rate or $\mathrm{C}$ reactive protein concentration. In one patient this occurred two weeks after the start of treatment with azathioprine, in two patients after four weeks of treatment, and in the remaining patient by the eighth week. All four patients reported low or no alcohol intake during the study period (high alcohol intake may cause a rise in $\gamma$-glutamyltransferase activity). ${ }^{4}$ Nephrotoxicity was not seen in these patients.

\section{Comment}

Comparison of $\mathrm{C}$ reactive protein concentration and erythrocyte sedimentacion rate in patients with high initial IgA concentrations, low initial IgA concentration, and low initial IgA concentration with subsequent hepatotoxicity showed that there was no significant difference in disease activity between these three groups. Furthermore, hepatotoxicity occurred only with azathioprine, and other drug toxicity did not seem to be associated with initial low serum IgA concentration.

We suggest that the apparent association between a low IgA concentration and the subsequent development of hepatotoxicity with azathioprine requires further clarification, but, at present, patients with a low IgA concentration starting treatment with azathioprine should be monitored particularly closely.

${ }^{1}$ Johns P, Felix-Davies DD, Hawkins CF, et al. IgA deficiency in patients with rheumatoid arthritis treated with D-penicillamine or gold. Ann Rheum Dis 1978;37:289.

' Delamere JP, Grindulis KA, Farr M. Effects on rheumatoid activity of drug-induced changes in serum immunoglobulins, particularly selective IgA deficiency. Ann Rheum Dis 1983;42:231.

${ }^{3}$ Spooner RJ, Smith DH, Bedford D, Beck PR. Serum gammaglutamyltransferase and alkaline phosphatase in rheumatoid arthritis. $\mathcal{F}$ Clin Pathol $1982 ; 35: 638-41$.

${ }^{4}$ Penn R, Worthington DJ. Is serum $\gamma$-glutamyltransferase a misleading test ? Br Med fै 1983;286:531-5.

(Accepted 12 May 1983)

Clinical Pharmacology Unit, Royal Bath Hospital, Harrogate,

Yorkshire HG1 2PS

C HARVEY, BSC, research technician

J S DIXON, BSC, PHD, lecturer

H A BIRD, MD, MRCP, lecturer and consultant rheumatologist

Correspondence to: Dr Bird. 